\title{
Can Brotherhood be Sold Like Soap...Online? An Online Social Marketing and Advocacy Pilot Study Synopsis
}

\author{
Brian Cugelman, Mike Thelwall, Phil Dawes \\ University of Wolverhampton \\ Statistical Cybermetrics Research Group and Wolverhampton Business School
}

\begin{abstract}
Having engaged one billion users by early 2006, the Internet is the world's fastest-growing mass communications medium. As it permeates into countless lives across the planet, it offers social campaigners an opportunity to deploy interactive interventions that encourage populations to adopt healthy living, environmental protection and community development behaviours. Using a classic set of social campaigning criteria, this paper explores relationships between social campaign websites and behavioural change.
\end{abstract}

Keywords: social marketing, advocacy, internet, online, behaviour, campaign

\section{Introduction and Background}

Over 50 years ago, the psychologist G. D. Wiebe asked the question 'Can brotherhood be sold like soap?' In his paper, 'Merchandising Commodities and Citizenship on Television'[1], Wiebe proposed that organizations which successfully 'sell' intangible social objects - such as goodwill, respect for the environment or community development-would be more successful if they sold their social objects the way marketers sell sports cars or mouth wash. To test this notion, Wiebe developed a set of five criteria (Table 1) and used them to evaluate how social campaigns compared to commercial marketing practices. After evaluating four social campaigns by his five criteria, Wiebe concluded that the more social campaigns resembled commercial marketing practices, the better their chance of success.

Beyond frequently quoting Wiebe's famous question, his criteria were deemed success factors for non-profit campaigns by the marketing authority Philip Kotler [2] who also compared them to marketing's $4 \mathrm{Ps}$ - product, price, place, promotion - in his 1971 article where he coined the term 'social marketing' [3]. Although Wiebe's criteria are over 50 years old, they still stand as success criteria for social campaigns; and with their conceptual relationship to the 4Ps - which are the primary behavioural exchange model used for social marketing (SM) - they provide a tested and relevant framework.

One meta-analysis that compared several web-based versus non-web-based health intervention studies showed that online programmes significantly increased participants' knowledge and health related behaviour [4]. A number of publications showcase counter campaigns that pit the 'good guys' against the 'bad guys' such as 
health campaigns against tobacco companies [5, 6] or drug use [7]. The most promising research addresses online persuasion. For example, a person's willingness to forward email is impacted by length, media attachments and positivity [8] while website loyalty is impacted by usability, trust and user satisfaction [9].

Table 1: Wiebe's (1951) criteria for campaign success

\begin{tabular}{|l|l|}
\hline \multicolumn{1}{|c|}{ Wiebe's (1951) criteria } & \multicolumn{1}{c|}{ Online application } \\
\hline $\begin{array}{l}\text { Force: The intensity of a person's motivation } \\
\text { (both before and after experiencing campaign } \\
\text { messages) towards a campaigns goal }\end{array}$ & $\begin{array}{l}\text { A person's disposition towards a social } \\
\text { issue is the same online or offline }\end{array}$ \\
\hline $\begin{array}{l}\text { Direction: Knowledge of how and where to } \\
\text { respond to a campaign's message; or in other } \\
\text { words, how to reach the social mechanism }\end{array}$ & $\begin{array}{l}\text { The clarity of an email, hyperlink, site } \\
\text { design or web advertisements that direct } \\
\text { people to a website (social mechanism) }\end{array}$ \\
\hline $\begin{array}{l}\text { Distance: An individual's estimate of the time, } \\
\text { energy and cost required to engage the social } \\
\text { mechanism or achieve the behavioural goal }\end{array}$ & $\begin{array}{l}\text { The amount of time, energy and hassle } \\
\text { required to find a website and complete an } \\
\text { online task }\end{array}$ \\
\hline $\begin{array}{l}\text { Social mechanism: The agency or place that } \\
\text { enables people to translate motivations into } \\
\text { actions }\end{array}$ & $\begin{array}{l}\text { A website or online application where } \\
\text { users can interact to complete behavioural } \\
\text { goals }\end{array}$ \\
\hline $\begin{array}{l}\text { Adequacy: Ability and effectiveness of the } \\
\text { social mechanism to help people act out the } \\
\text { campaign's behavioural goal }\end{array}$ & $\begin{array}{l}\text { The degree of credibility, and intuitiveness } \\
\text { of a website's social mechanism }\end{array}$ \\
\hline
\end{tabular}

Using Wiebe's five criteria as a framework, this paper presents the findings from a pilot study intended to identify factors of online campaigns that influence users' behaviour.

\section{Case Study and Methods}

In 2005, the Global Call to Action against Poverty - an international anti-poverty campaign in over 100 countries - pressured world leaders to meet commitments on poverty, development, trade and debt; while advocating the United Nations' Millennium Development Goals. In 2006, an in-depth assessment of the campaign's 48 websites [10] was conducted on behalf of the campaign's secretariat, the NGO network Worldwide Alliance for Citizen Participation (CIVICUS).

Having been requested to evaluate the campaign's SM and advocacy capacity, Wiebe's criteria and behavioural change impact questions were built into the research tools. An online survey - in English, French and Spanish - ran from January to May 2006, obtaining 196 user responses from 23 of the 48 websites. For this pilot study, the independent variables (IV) came from questions inspired by Wiebe's criteria — or with clear conceptual linkages - and were grouped into his five criteria. The dependent variable (DV) was derived from the question, 'As a result of this website have you noticed a change in your willingness to take action?'

Correlation and linear regression were used to examine the associations between each of Wiebe's five criteria and the DV. All strong associations are highlighted; while 
many insignificant relations are not featured due to space limitations in this synopsis. There are a number of limitations. First, this pilot study uses data intended for a broad review with face-value questions. Second, the grouping of some questions by Wiebe's criteria could be challenged on the basis of ambiguous conceptual fits. Third, the study was conducted while the campaign was in a dormant state and respondents are likely to represent loyal users. Fourth, the three survey languages may have contributed a degree of bias. For these reasons, this study only claims to be an exploratory pilot study.

\section{Findings and Conclusions}

When examining the relationships between Wiebe's five criteria and the DV, standard demographics - such as sex, age, occupation, nationality or the way users accessed the Internet—showed no significant associations.

Table 2: The regression models for each criteria group

\begin{tabular}{|c|c|c|c|c|c|c|}
\hline Criteria & $\operatorname{Adj} R^{2}$ & ANOVA \pm & Variables & B & SE B & $\boldsymbol{\beta}$ \\
\hline \multirow[t]{3}{*}{ Force } & .194 & $\mathrm{~F}(3,154)$ & Motivated by site information & .427 & .155 & $.214 * *$ \\
\hline & & $=12.365$ & Motivated by national issues & .445 & .130 & $.254 * * *$ \\
\hline & & & Number of topical interests & .034 & 016 & $.161^{*}$ \\
\hline \multirow[t]{2}{*}{ Direction } & .142 & $F(2,156)$ & Finding information on the site & .198 & .089 & $.205^{*}$ \\
\hline & & $=14.125$ & Website's layout \& design & .198 & .078 & $.233 *$ \\
\hline Distance & .077 & $\begin{array}{l}\mathrm{F}(1,143) \\
=13,096\end{array}$ & Time \& energy demanded & .206 & .057 & $.290 * * * *$ \\
\hline \multirow{2}{*}{$\begin{array}{l}\text { Mechanis } \\
\text { m }\end{array}$} & .208 & $\mathrm{~F}(2,155)$ & Social networking options & .186 & .065 & $.242 * *$ \\
\hline & & $=21.587$ & Activism options & .226 & .066 & $.289 * * *$ \\
\hline \multirow[t]{2}{*}{ Adequacy } & .246 & $\mathrm{~F}(2,148)$ & Helpful to studies or interests & .215 & .065 & $.280 * * *$ \\
\hline & & $=25.491$ & Content \& information quality & .235 & .068 & $.295^{* * *}$ \\
\hline
\end{tabular}

While fitting the linear regression model (Table 2), each of Wiebe's criteria were evaluated separately; only distance behaved unexpectedly. The strongest force variables showed that target audiences who did the most, visited the site frequently and considered themselves campaign supporters. However, these variables were highly correlated with the other IV and were removed from the model. Celebrities drove many people to the campaign websites; however, website information was more associated with the DV. Users driven by national issues in their home country and who were interested in a broad number of social causes were the most active. The direction variables showed that better designed and more usable websites were more persuasive. Users were more active on sites with better rated layout, design and findability. The social mechanism variables showed that sites with the biggest impact on user's willingness to take action had more online advocacy mechanisms (such as e-petitions) and more opportunities for users to interact. The adequacy variables showed that the quality of the online social mechanism related to mobilization success. Users' rating of 
website credibility was removed from the model due to its very high correlation with the other IV. Content, information quality and a sites' helpfulness related to the IV. The distance variables showed that website users were willing to expend considerable time and energy to participate in the campaign. SM literature advocates that people are unlikely to act if behavioural objectives are too inconvenient, unpleasant or costly [11]. This difference, and whether or not users consider themselves supporters, may mark key delimiters between populations that are receptive to advocacy versus SM.

Though this analysis compared Wiebe's criteria to a user's willingness to take action, the survey also considered two other behavioural variables: first, the total number of reported actions taken and second, users' visit frequency. Combined with the DV these three behavioural variables had a Cronbach's Alpha of 0.62 which shows acceptable consistency among the survey's three separate behavioural measures. Online marketing literature provides a basis for explaining the association between visits and behaviour. Termed 'loyalty', online marketing consider visit frequency a precursor to two behavioural objective: opting-in to newsletters and buying products [9].

Wiebe's five criteria proved to be a useful broad framework for organizing a number of key online campaigning attributes. However, conceptual overlap and statistical pressure to arrange the variables in different ways supports the conclusion that each of Wiebe's five criteria are a good basic set of requirements for effective campaigns, but they cannot provide an overall framework the growing body of research related to online behavioural change.

\section{References}

1. Wiebe, G.D., Merchandising Commodities and Citizenship on Television. Public Opinion Quarterly, 1951. 15 (4): p. 679.

2. Kotler, P. and E. Roberto, Social Marketing. 1989, New York: The Free Press.

3. Kotler, P. and G. Zaltman, Social Marketing: An Approach to Planned Social Change. Journal of Marketing, 1971. $35(3,2)$.

4. Wantland, D., et al., The effectiveness of web-based vs. non-web-based interventions: a metaanalysis of behavioural change outcomes. Journal of Medical Internet Research, 2004. 6(4).

5. Ribisl, K., The potential of the Internet as a medium to encourage and discourage youth tobacco use. Tobacco Control, 2003. 12: p. 48-59.

6. Lin, C. and G. Hullman, Tobacco-prevention messages online: social marketing via the web. Health Communication, 2005. 18(2): p. 177-193.

7. King, L., Using the Internet to facilitate and support health behaviors. Social Marketing Quarterly, 2004. 10(2): p. 72-78.

8. Lin, T., et al., Why are some e-mails forwarded and others not? Internet Research, 2006. 16(1): p. 81-93.

9. Flavian, C., M. Guinaliu, and R. Gurrea, The role played by perceived usability, satisfaction and consumer trust on website loyalty. Information and Management, 2004.

10. Cugelman, B. and K. Kumar, GCAP Review of Campaign Websites. 2006, CIVICUS.

11. McKenzie-Mohr, D., Promoting a sustainable future: an introduction to community-based social marketing. 1995, Ottawa: National Round Table on the Environment and the Economy. 